\title{
EVALUATION OF TETRA-n-BUTYLAMMONIUM BROMIDE AS CORROSION INHIBITOR FOR MILD STEEL IN 1N HCI MEDIUM: EXPERIMENTAL AND THEORETICAL INVESTIGATIONS
}

\author{
N. Subasree, J. Arockia Selvi*, M. Arthanareeswari, and Renjith S. Pillai \\ Department of Chemistry, SRM Institute of Science and Technology, \\ Kattankulathur-603203, (Tamil Nadu) India \\ *E-mail: arockiaj@srmist.edu.in
}

\begin{abstract}
The corrosion inhibition behavior of Tetra-n-butylammonium bromide (TBAB) on mild steel (MS) in $1 \mathrm{~N} \mathrm{HCl} \mathrm{was}$ investigated through experimental and theoretical studies. Inhibition efficiency is found to have increased by a rise in the concentration of TBAB. Experimental (weight loss study, potentiodynamic polarization, electrochemical impedance spectroscopy) results suggested that TBAB exhibits better inhibition efficiency. Thermodynamic studies were discussed. TBAB on the mild steel surface obey Langmuir adsorption isotherm. SEM and AFM studies confirm the adsorption and protective ability of TBAB on mild steel in $1 \mathrm{~N} \mathrm{HCl} \mathrm{medium.} \mathrm{Formation} \mathrm{of} \mathrm{a} \mathrm{protective}$ layer on mild steel was characterized by FT-IR, UV-Visible and XRD studies. Furthermore, quantum chemical parameters were calculated. The results demonstrate the adsorption capability of TBAB on mild steel in $1 \mathrm{~N} \mathrm{HCl}$ medium. Quantum chemical calculations are in good agreement with results obtained from experimental methods.
\end{abstract} Keywords: Corrosion Inhibition, Weight Loss Method, Polarization Sudy, XRD, AFM

(C) RASĀYAN. All rights reserved

\section{INTRODUCTION}

Excessive corrosion on metals or alloys occurs in aggressive environments during descaling, cleaning, and acid pickling industrial processes. ${ }^{1,2}$ Corrosion of mild steel has drawn attention for its substantial application in industries as construction materials and it also attributes a good mechanical strength, low cost, and easy fabrication. ${ }^{3}$ To prevent corrosion, the metal surface is significantly masked with an inhibitive species to isolate from the corrosive environment. ${ }^{4-6}$ The utilization of organic molecules as a corrosion inhibitor is a practical method to protect the metal from dissolution in acid media. ${ }^{7,8}$ Heterocyclic based quaternary ammonium compounds (surfactants) are reported as effective inhibitors to reduce the surface tension of one or more components in an acidic environment. ${ }^{9-11}$ Heterocyclic compounds having a $\pi$-conjugated double or triple bonds with heteroatoms $(\mathrm{S}, \mathrm{P}, \mathrm{N}$, etc.) show remarkable corrosion inhibition. Interaction occurring among the heterocyclic compounds and surface of the metal through the adsorption centers leads to the formation of a protective layer on mild steel surfaces. ${ }^{12-14}$ They get formed either by physisorption or chemisorption. Adsorption depends on physicochemical properties such as a) structure of molecules, b) $\pi$ - orbital character, and c) electronic density of the donor atoms. ${ }^{15-17}$ To reveal the nature of the interaction between the organic molecules and the metal surface, computational chemical methods are used as an important tool. The structure and electronic parameters of the inhibitor molecule can be obtained by means of theoretical calculations from the computational methodology. The increase in inhibition efficiency by 2, 5-dichloroaniline is revealed by quantum chemical calculation and is found to be due to the increase of HOMO Level which easily provides the free electrons to the metal surface. ${ }^{18}$ Similarly, pyridazine ring interaction with metallic atoms by electron density distributions of the FMOs is justified by computational quantum chemical methods. ${ }^{29}$ Very few studies are carried out using the computational methodology for TBAB as a corrosion inhibitor and as well in $\mathrm{HCl}$ medium.

Rasayan J. Chem., 13(1), 499-513(2020)

http://dx.doi.org/10.31788/RJC.2020.1315485

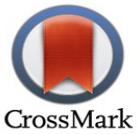




\section{RASĀYAN J. Chem.}

Vol. 13 | No. 1 |499 - 513| January - March | 2020

In the present work, we have attempted to study the consequence of tetra-n-butylammonium bromide in an environment of $1 \mathrm{NHCl}$ on mild steel. The corrosion prohibition capability of the TBAB on the substrate was examined through experimental and theoretical methods. Inhibition property was checked by the mass loss method, electrochemical studies, SEM, EDAX analysis, XRD, UV-Vis, FT-IR, AFM, and computational study. Weight loss studies carried out at dissimilar temperatures were familiar to draw Langmuir adsorption isotherm. Thermodynamic parameters attained from isotherms illustrate the interactive mode of tetra-n-butylammonium bromide over the metal specimen.

\section{Material}

\section{EXPERIMENTAL}

The elemental composition of the mild steel specimen (in \% by weight) chosen in the present study: C0.067, Mn-1.65, Si-0.145, S-0.006, P-0.02, Ni-0.04, Cr-0.198 and Fe balance. Mild steel specimens were polished with emery sheets (from grade 400-1200), degreased with acetone, washed with distilled water and finally dried in hot air. An aggressive medium of $1 \mathrm{NHCl}$ was prepared by using the analytical grade of $36 \% \mathrm{HCl}$ and distilled water. $1 \%$ stock solution of inhibitor, tetra-n-butylammonium bromide of analytical grade was prepared. Concentrations ranging from $100-500 \mathrm{ppm}$ of TBAB were used for the study.

\section{Weight Loss Studies}

Weight loss experiments have been carried out by immersing triplicate specimens in $1 \mathrm{NHCl}$ containing numerous TBAB concentrations at diverse temperatures ranging from $298 \mathrm{~K}$ to $328 \mathrm{~K}$ for about $1 \mathrm{~h}$. After 1h, immersed metal samples were washed, dried, and re-weighed. The corrosion rate (CR) and inhibition efficiency (IE \%) were calculated by the following expressions: ${ }^{19}$

$$
\begin{aligned}
& I E(\%)=\frac{W_{B}-W_{I}}{W_{B}} \times 100 \\
& C R(m m p y)=\frac{87.6 \times W}{A D T} \\
& \theta=\frac{I E(\%)}{100}
\end{aligned}
$$

Where, $\mathrm{W}_{\mathrm{I}}$ and $\mathrm{W}_{\mathrm{B}}$ are the weight loss of inhibited and uninhibited mild steel specimens. W, A, D, T, and $\Theta$ are the weight loss $(\mathrm{mg})$, area $\left(\mathrm{cm}^{2}\right)$, density $\left(\mathrm{g} \mathrm{cm}^{-3}\right)$, immersion time (h), and surface coverage of metal specimen.

\section{Electrochemical Studies}

Electrochemical studies were performed using Biologic SP300 through a conventional three-electrode cell system consisting of mild steel as a working electrode, platinum wire as counter electrode and $\mathrm{Ag} / \mathrm{AgCl}$ as a reference electrode ${ }^{20}$. The working electrode was immersed in $1 \mathrm{~N} \mathrm{HCl}$ at different concentrations of TBAB. Tafel curves were performed with a potential range of -0.025 to $+0.025 \mathrm{mV}$ at a scanning rate of $1 \mathrm{mVs}^{-1}$. Electrochemical impedance experiments were performed with a frequency range of 100000 to $0.010 \mathrm{~Hz}$ and an amplitude of $10 \mathrm{mV}$. The results have been fitted using EC-Laboratory software.

\section{Surface Analysis}

FT-IR and UV-Vis spectrum were recorded by Agilent Resolution Pro FT-IR spectrophotometer and Labman Scientific Instrument Pvt. Ltd double beam UV-Visible spectrophotometer respectively. XRD was carried out with XRD-PAN analytical X'pert powder Diffract meter using $\mathrm{Cu}-\mathrm{K} \alpha$ radiation ( $\lambda=$ $0.15405 \AA$ ). The surface morphological studies were performed using Field Emission Scanning Electron Microscope (FESEM) FEI quanta FEG 200 with an energy dispersive X-ray analyzer. AFM studies were performed by Scanning Probe Microscope 5100 Pico LE (Agilent Technologies).

\section{Computational Studies}

Frontier Molecular Orbital has been studied after the geometric optimization of TBAB and all theoretical calculations were carried out using the Gaussian 16 software $^{21}$ to explore the characteristics of inhibitor. 
RASĀYAN J. Chem.

Vol. 13 | No. 1 |499 - 513| January - March | 2020

The molecular structure of the inhibitor, TBAB, was optimized by the density functional theory (DFT) with B3LYP correlation functional ${ }^{22-23}$ and the $6-31 \mathrm{G}(\mathrm{d}, \mathrm{p})$ basis set. Computations were carried out using the dipole moment $(\mu)$, ionization potential (I), electron affinity (A), electronegativity $(\chi)$, global hardness $(\eta)$, and number of transferred electrons $(\Delta N)$ were calculated by following equations:,

$\mathrm{I}=-\mathrm{E}_{\text {HОМО }}$

$\mathrm{A}=-\mathrm{E}_{\mathrm{LUMO}}$

$x=\frac{(I+A)}{2}$

$\eta=\frac{(I-A)}{2}$

$\Delta \mathrm{N}=\frac{\chi_{\mathrm{Fe}}-\chi_{\mathrm{inh}}}{2\left(\mathrm{n}_{\mathrm{Fe}}-\eta_{\mathrm{inh}}\right)}$

\section{Weight Loss Studies}

RESULTS AND DISCUSSION

The corrosion rate and the inhibition efficiencies were plotted against different concentrations of TBAB for mild steel immersed in $1 \mathrm{~N} \mathrm{HCl}$ for about 1 hour at room temperature $(298 \mathrm{~K})$ are shown in Fig.-1. The results reveal (in Fig.-1) inhibition efficiency increases and the rate of corrosion decrease with an increase in the concentration of TBAB. Inhibitor performance at various concentrations is shown in Table- 1 . The highest inhibition efficiency of $93 \%$ was observed for $500 \mathrm{ppm}$ of TBAB. It is attributed due to the adsorbed inhibitor molecules to the active sites of the mild steel surface, replacing the water molecule and chloride ions.

Table-1: Inhibitor Performance of Mild Steel in 1N HCl Solution with and without TBAB at 298K

\begin{tabular}{c|c|c|c}
\hline Conc.(ppm) & CR $(\mathrm{mm} / \mathrm{y})$ & $\Theta$ & IE (\%) \\
\hline 0 & 168.17 & - & 46 \\
\hline 100 & 89.38 & 0.46 & 53 \\
\hline 200 & 77.34 & 0.53 & 68 \\
\hline 300 & 52.93 & 0.68 & 85 \\
\hline 400 & 24.85 & 0.85 & 93 \\
\hline 500 & 11.14 & 0.93 & \\
\hline
\end{tabular}

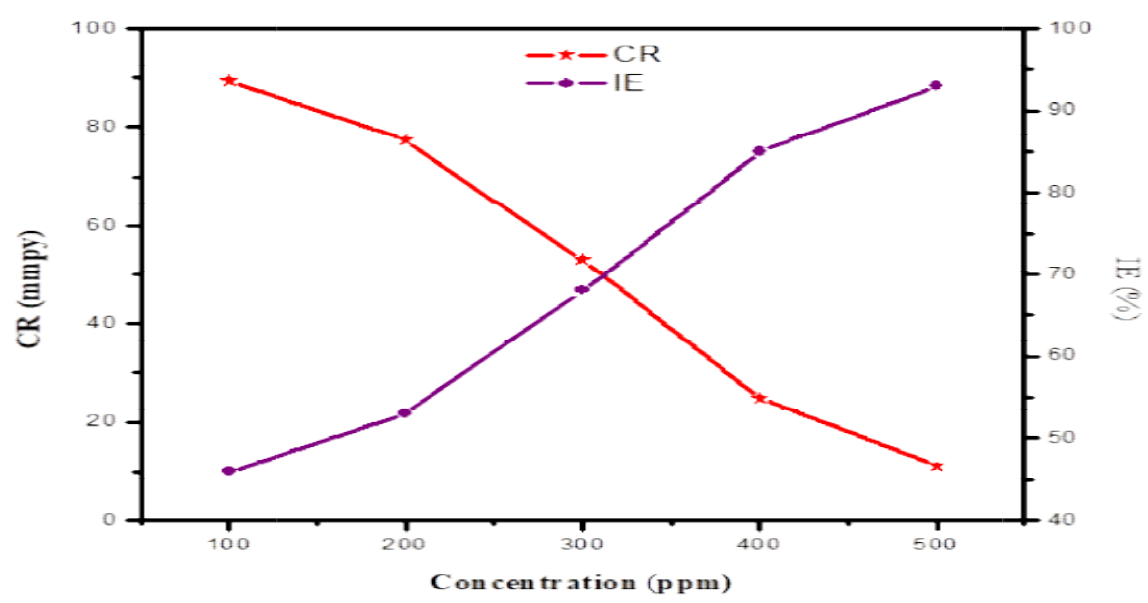

Fig.-1: The Corrosion Rate and the Inhibition Efficiencies at Different Concentrations of TBAB for Mild Steel immersed in $1 \mathrm{~N} \mathrm{HCl}$ for about 1 hour at $298 \mathrm{~K}$

\section{Consequences of Temperature And Thermodynamic Parameters}

Table-2 lists inhibition efficiency of TBAB and corrosion rate of mild steel in $1 \mathrm{~N} \mathrm{HCl}$ with the increase in temperature from $298 \mathrm{~K}$ to $328 \mathrm{~K}$. The table shows that the effectiveness of inhibition reduces from $93 \%$ to $41 \%$ for TBAB at $500 \mathrm{ppm}$ with the rise in temperature. ${ }^{24}$ The decrease in inhibition efficiency revealed the physical adsorption occurring between $\mathrm{TBAB}$ and the mild steel, while the corrosion rate increases 
RASĀYAN J. Chem.

Vol. 13 | No. 1 |499 - 513| January - March | 2020

due to the desorption of inhibitor molecules from the mild steel surface (Fig.-2). The activation energy of the corrosion studied according to the Arrhenius equation is given by:

$$
C R=A \exp \frac{-E_{a}}{R T}
$$

Where, $E_{a}$ is the corrosion activation energy, $A$ is a frequency factor, $T$ is a temperature in Kelvin, and $R$ is the gas constant. The Arrhenius plots, $\log \mathrm{CR}$ Vs 1000/T of mild steel in $1 \mathrm{~N} \mathrm{HCl}$ at the range of temperature, $298 \mathrm{~K}-328 \mathrm{~K}$ is presented in Fig.-3. The values of $\mathrm{E}_{\mathrm{a}}$ were determined from the slope of the linear line and are presented in Table-3. From the table that the $\mathrm{E}_{\mathrm{a}}$ value increased from $27.50 \mathrm{~kJ} \mathrm{~mol}^{-1}$ to $39.15 \mathrm{~kJ} \mathrm{~mol}^{-1}$ with increasing inhibitor concentrations. Increasing $\mathrm{E}_{\mathrm{a}}$ value shows the prevention of charge/mass transfer reaction between the mild steel and corrosion medium. ${ }^{25}$ However, the increase in $\mathrm{E}_{\mathrm{a}}$ values shows the physical adsorption of the inhibitor molecules on the metal surface and which decreases appreciably with an increase in temperature. ${ }^{26}$ The entropy and the enthalpy of activation of the corrosion process were calculated using the following relation,

$C R=\frac{R T}{N h} \exp \left(\frac{\Delta S}{R}\right) \exp \left(\frac{-\Delta H}{R T}\right)$

Where, $\mathrm{N}$ is the Avogadro number, and $\mathrm{h}$ is the Planck's constant. Figure-4 shows the graph of $\mathrm{CR} / \mathrm{T}\left(\mathrm{K}^{-1}\right)$ Vs. $1000 / T\left(\mathrm{~K}^{-1}\right)$. The obtained linear line with a slope of $\Delta \mathrm{S}$ and intercept of $\Delta \mathrm{H}$ are shown in Table-3. Positive values of $\Delta \mathrm{H}$ direct the endothermic behavior for mild steel corrosion in the $1 \mathrm{~N} H C l$ medium. The negative values of entropy or decrease in entropy values confirm that the activated complex is of lower order containing inhibitor. ${ }^{27}$ That is the protective film formed above the metal specimen becomes well-ordered ${ }^{28}$.

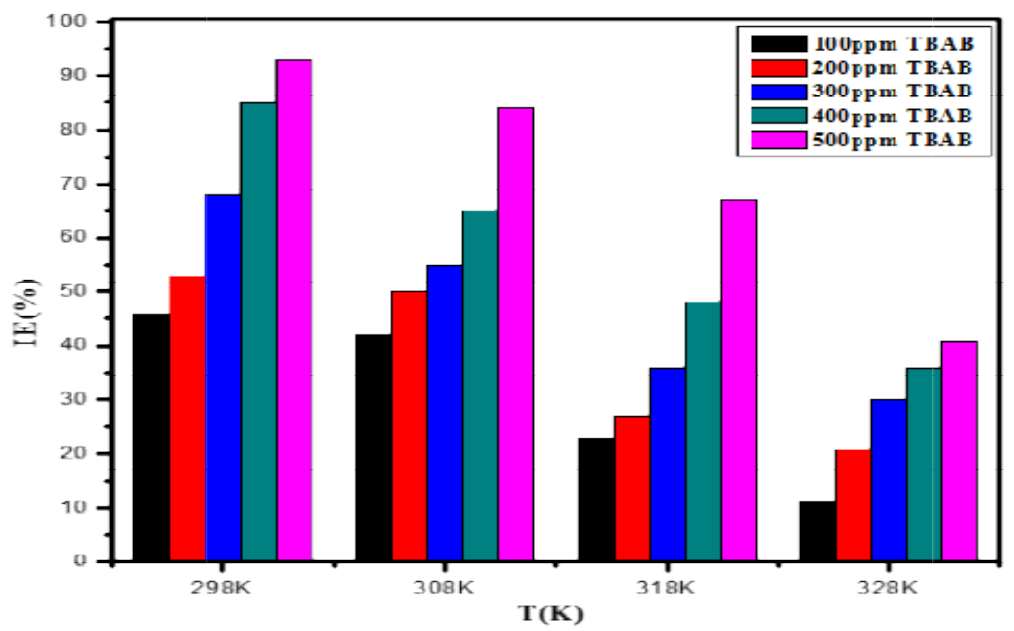

Fig.-2: Inhibition Efficiency (IE\%) for Mild Steel in $1 \mathrm{NHCl}$ with Altered Concentrations of TBAB at 298K - 328K

Table-2: The Results of Weight Loss Measurement in the Absence and Presence of TBAB at $298 \mathrm{~K}-328 \mathrm{~K}$

\begin{tabular}{c|c|c|c|c|c|c|c|c}
\hline \multirow{2}{*}{$\begin{array}{c}\text { Conc. } \\
(\mathrm{ppm})\end{array}$} & \multicolumn{2}{|c|}{$298 \mathrm{~K}$} & \multicolumn{2}{c|}{$308 \mathrm{~K}$} & \multicolumn{2}{c|}{$318 \mathrm{~K}$} & \multicolumn{2}{c}{$328 \mathrm{~K}$} \\
\cline { 2 - 9 } & $\begin{array}{c}\mathrm{CR} \\
(\mathrm{mm} / \mathrm{y})\end{array}$ & $\begin{array}{c}\mathrm{IE} \\
(\%)\end{array}$ & $\begin{array}{c}\mathrm{CR} \\
(\mathrm{mm} / \mathrm{y})\end{array}$ & $\begin{array}{c}\mathrm{IE} \\
(\%)\end{array}$ & $\begin{array}{c}\mathrm{CR} \\
(\mathrm{mm} / \mathrm{y})\end{array}$ & $\begin{array}{c}\mathrm{IE} \\
(\%)\end{array}$ & $\begin{array}{c}\mathrm{CR} \\
(\mathrm{mm} / \mathrm{y})\end{array}$ & $\begin{array}{c}\mathrm{IE} \\
(\%)\end{array}$ \\
\hline Blank & 166.17 & - & 46.14 & - & 36.33 & - & 28.08 & - \\
\hline 100 & 89.38 & 46 & 26.30 & 43 & 31.65 & 13 & 24.96 & 11 \\
\hline 200 & 77.34 & 53 & 22.62 & 51 & 24.29 & 33 & 21.95 & 22 \\
\hline 300 & 52.98 & 68 & 20.50 & 56 & 21.73 & 40 & 19.61 & 30 \\
\hline 400 & 24.85 & 85 & 15.82 & 66 & 14.82 & 59 & 17.94 & 36 \\
\hline 500 & 11.14 & 93 & 7.35 & 84 & 11.36 & 69 & 16.49 & 41 \\
\hline
\end{tabular}


RASĀYAN J. Chem.

Vol. 13 | No. 1 |499 - 513| January - March | 2020

Table-3: Activation Energy and Thermodynamic Parameters of TBAB on the Specimen Surface immersed in $1 \mathrm{NHCl}$ at $298 \mathrm{~K}-328 \mathrm{~K}$

\begin{tabular}{c|c|c|c}
\hline $\begin{array}{c}\text { Conc } \\
(\mathrm{ppm})\end{array}$ & $\begin{array}{c}\mathrm{E}_{\mathrm{a}} \\
\left(\mathrm{kJ} \mathrm{mol}^{-1}\right)\end{array}$ & $\begin{array}{c}\Delta \mathrm{H}^{*} \\
\left(\mathrm{~kJ} \mathrm{~mol}^{-1}\right)\end{array}$ & $\begin{array}{c}-\Delta \mathrm{S}^{*} \\
\left(\mathrm{~J} \mathrm{~mol}^{-1} \mathrm{k}^{-1}\right)\end{array}$ \\
\hline 0 & 27.50 & 61.50 & 86.52 \\
\hline 100 & 31.79 & 60.93 & 87.39 \\
\hline 200 & 34.05 & 62.18 & 82.48 \\
\hline 300 & 34.86 & 62.59 & 79.93 \\
\hline 400 & 38.76 & 63.13 & 77.01 \\
\hline 500 & 39.15 & 68.11 & 75.22 \\
\hline
\end{tabular}

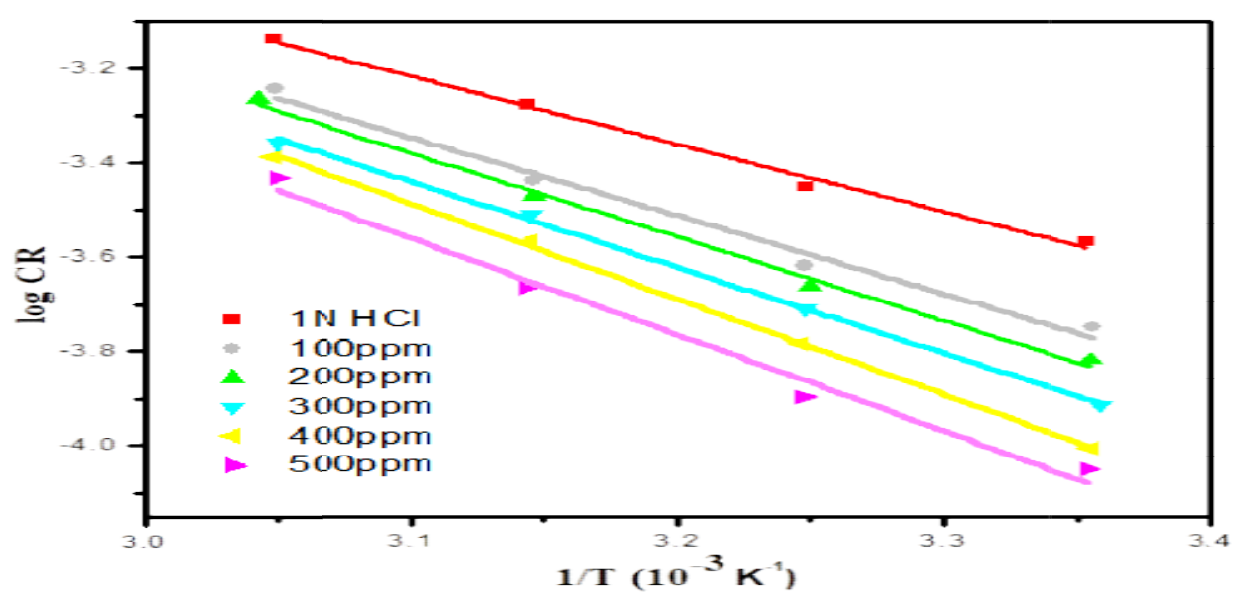

Fig.-3: Arrhenius Plots of Mild Steel Corrosion in $1 \mathrm{~N} \mathrm{HCl}$ in Diverse Concentrations of TBAB at $298 \mathrm{~K}-328 \mathrm{~K}$

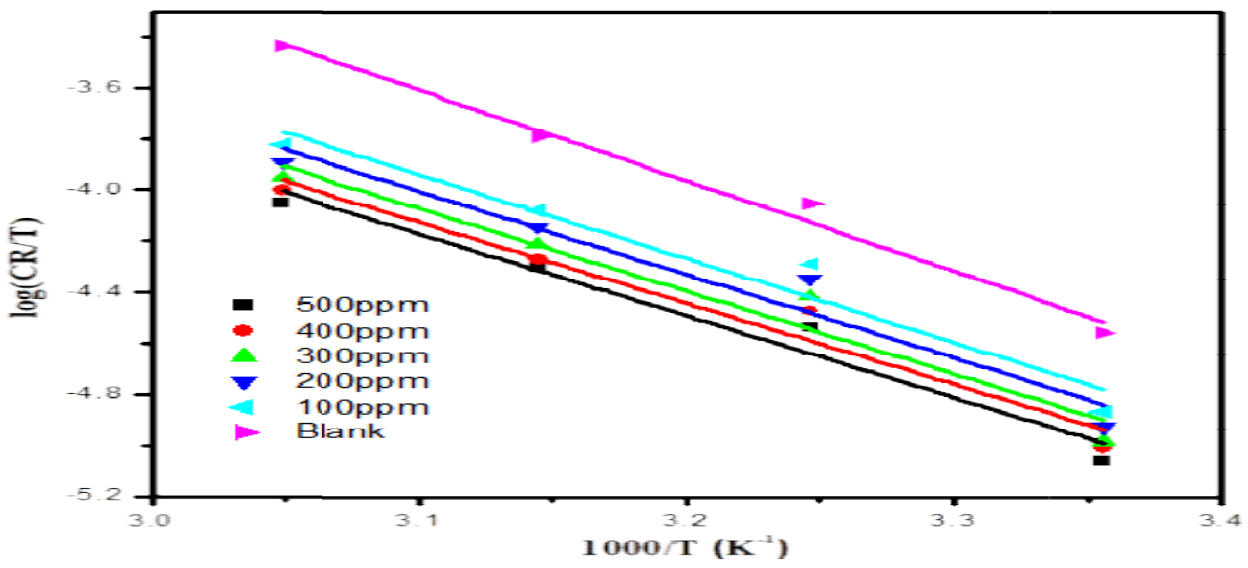

Fig.-4: Transition State Plots for Mild Steel in $1 \mathrm{~N} \mathrm{HCl}$ with and without TBAB at $298-328 \mathrm{~K}$

\section{Adsorption Isotherm}

The adsorption isotherm is used for learning the inhibitory action through the interaction among the inhibitor molecules and the metal surface during the inhibition process. The adsorption mode depends on the inhibitor structure, temperature and corrosion potential of the metal/medium interface. ${ }^{29-30}$ Surface coverage values used to study the adsorption isotherm. By Langmuir adsorption isotherm, the surface coverage $(\Theta)$ obtained from weight loss data is related to the adsorption constant $\left(\mathrm{K}_{\mathrm{ads}}\right)$ and the inhibitor concentration $\left(\mathrm{C}_{\text {inh }}\right)$ as in the following equation:

$\frac{\mathrm{C}_{\mathrm{inh}}}{\theta}=\frac{1}{\mathrm{~K}_{\mathrm{ads}}}+\mathrm{C}_{\mathrm{inh}}$ 
RASĀYAN J. Chem.

Vol. 13 | No. 1 | 499 - 513| January - March | 2020

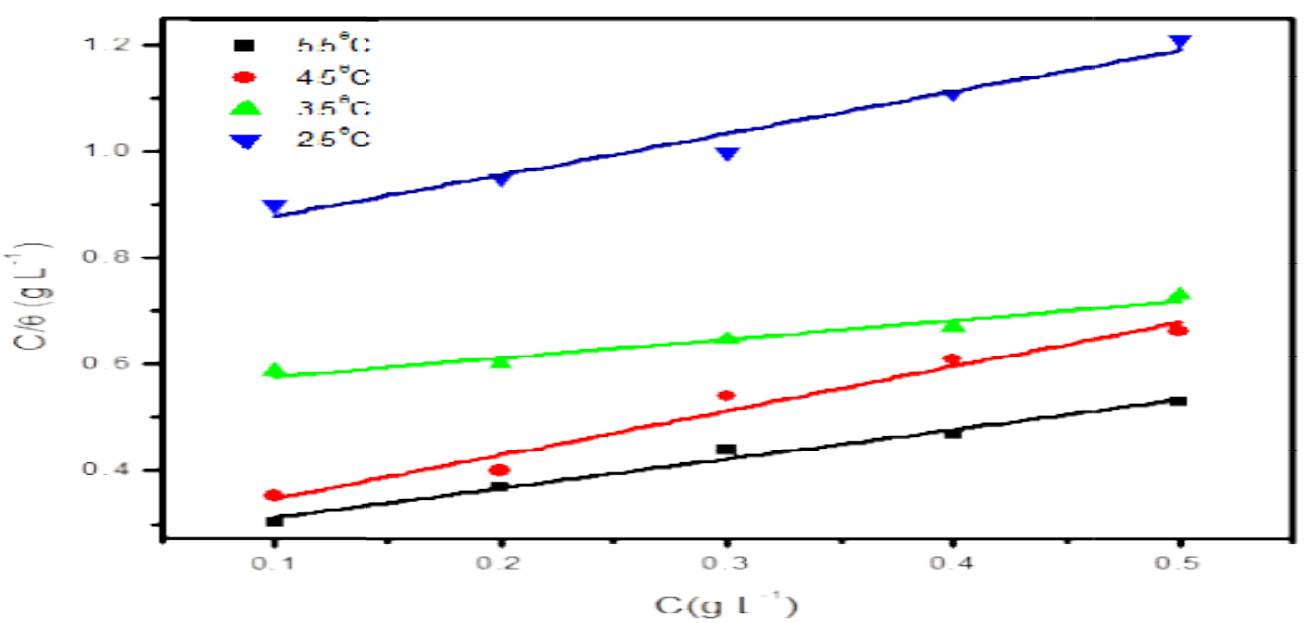

Fig.-5: Langmuir Adsorption Isotherm for TBAB on Mild Steel Surface immersed in 1N HCl at 298K-328K

Table-4: $\mathrm{K}_{\mathrm{ads}}$ and $\Delta \mathrm{G}_{\mathrm{ads}}$ of TBAB on Mild Steel immersed in $1 \mathrm{NHCl}$ at $298 \mathrm{~K}-328 \mathrm{~K}$

\begin{tabular}{c|c|c|c}
\hline $\begin{array}{c}\text { Temperature } \\
(\mathrm{K})\end{array}$ & $\mathrm{R}^{2}$ & $\begin{array}{c}\mathrm{K}_{\mathrm{ads}} \\
\left(\mathrm{L} \mathrm{g}^{-1}\right)\end{array}$ & $\begin{array}{c}\Delta \mathrm{G}_{\mathrm{ads}} \\
\left(\mathrm{kJ} \mathrm{mol}^{-1}\right)\end{array}$ \\
\hline 298 & 0.9592 & 3.13 & -12.78 \\
\hline 308 & 0.9802 & 2.15 & -12.25 \\
\hline 318 & 0.9559 & 0.97 & -10.55 \\
\hline 328 & 0.9428 & 0.65 & -9.80 \\
\hline
\end{tabular}

Langmuir plot $\left(\mathrm{C} / \Theta\right.$ against $\mathrm{C}$ ) displays a linear line as exposed in Figure 5 with $\mathrm{R}^{2}$ data close to 0.9802 for TBAB at $298 \mathrm{~K}-328 \mathrm{~K}$. The best fit of $\mathrm{R}^{2}$ indicates that the TBAB adsorption on the metal surface obeys the Langmuir adsorption isotherm. The values of $\mathrm{K}_{\mathrm{ads}}$ and $\Delta \mathrm{G}_{\mathrm{ads}}$ are assumed in Table 4 . The data in the table clearly show that $K_{\mathrm{ads}}$ decrease with rising temperature. This indicates adsorbed inhibitor molecules on the mild steel that can desorb by increasing temperature. The $\mathrm{K}_{\mathrm{ads}}$ can be correlated to calculate adsorption free energy by following relation: ${ }^{31}$

$\Delta \mathrm{G}_{\mathrm{ads}}=-\mathrm{RT} \ln 55.5 \mathrm{~K}_{\mathrm{ads}}$

Where, $\mathrm{R}$ is the gas constant, and $\mathrm{T}$ is the temperature.

The negative values of free energy adsorption suggest that the adsorption of TBAB is spontaneous. Usually, $\Delta \mathrm{G}_{\text {ads }}$ values are less than $-40 \mathrm{~kJ} \mathrm{~mol}^{-1}$ is related to physical adsorption, while $\Delta \mathrm{G}_{\text {ads }}$ values around $-40 \mathrm{~kJ} \mathrm{~mol}^{-1}$ or higher are consistent with chemical adsorption as a result of the transfer or sharing of electrons from the inhibitor molecule to the metal surface ${ }^{32}$. For the studied inhibitor TBAB, the $\Delta \mathrm{G}_{\mathrm{ads}}$ values are less than $-20 \mathrm{KJ} \mathrm{mol}^{-1}$ designates TBAB adsorption is the physisorption type.

\section{Electrochemical Studies}

\section{Potentiodynamic Polarization Studies}

Figure. 6 displays a polarization graph for mild steel in the test solution without and with TBAB. Polarization parameters comprise Tafel anodic slopes and Tafel cathodic slopes, corrosion potential $\left(\mathrm{E}_{\text {corr }}\right)$, corrosion current density $\left(\mathrm{I}_{\text {corr }}\right)$, corrosion rate, and inhibition efficiency are shown in Table-5. It is observed that the increase of concentration of inhibitor, decreases the Icorr values. The $\mathrm{E}_{\text {corr }}$ values suggest that the inhibitor acts as anodic as well as cathodic on account of unnoticeable difference in the $\mathrm{E}_{\text {corr }}$ values between the inhibited and uninhibited system.

Corrosion rate (CR) and inhibition efficiency (IE\%) are calculated by following equations: ${ }^{33}$ 
RASĀYAN J. Chem.

Vol. 13 | No. 1 |499 - 513| January - March | 2020

$\mathrm{CR}(\mathrm{mm} / \mathrm{y})=\frac{0.00327 \times \mathrm{I}_{\text {corr }} \times \mathrm{Eq} \cdot \mathrm{wt}}{\mathrm{D}}$

$I E(\%)=\frac{I_{c o r r}^{0}-I_{\text {corr }}}{I_{\text {corr }}^{0}} \times 100$

In the equation, $\mathrm{I}_{\text {corr }}$ and $\mathrm{I}_{\text {corr }}$ are the corrosion current densities of mild steel without and with TBAB in $1 \mathrm{~N} \mathrm{HCl}$, respectively. The best efficiency of TBAB is about $89.66 \%$ at $500 \mathrm{ppm}$.

Table-5: Tafel Parameters for Mild Steel in 1NHCl Solutions without and with TBAB

\begin{tabular}{c|c|c|c|c|c|c}
\hline $\begin{array}{c}\text { Conc. } \\
(\mathrm{ppm})\end{array}$ & $\begin{array}{c}-\mathrm{E}_{\text {corr }} \\
(\mathrm{mV})\end{array}$ & $\begin{array}{c}\mathrm{I}_{\text {corr }} \\
\left(\mu \mathrm{A} \mathrm{cm}^{-2}\right)\end{array}$ & $\begin{array}{c}\beta_{\mathrm{a}} \\
(\mathrm{mV} / \mathrm{dec})\end{array}$ & $\begin{array}{c}\beta_{\mathrm{c}} \\
(\mathrm{mV} / \mathrm{dec})\end{array}$ & $\begin{array}{c}\mathrm{CR} \\
(\mathrm{mm} / \mathrm{y})\end{array}$ & $\begin{array}{c}\mathrm{IE} \\
(\%)\end{array}$ \\
\hline Blank & 481.951 & 1291.444 & 31.7 & 34.6 & 1.51391 & - \\
\hline 100 & 479.421 & 1121.774 & 38.9 & 38.8 & 1.31501 & 13.13 \\
\hline 200 & 480.496 & 1061.505 & 29.5 & 29.2 & 1.24436 & 17.80 \\
\hline 300 & 470.016 & 418.723 & 35.8 & 33.4 & 0.490852 & 67.57 \\
\hline 400 & 465.133 & 340.087 & 22.9 & 25.7 & 0.39867 & 73.66 \\
\hline 500 & 462.801 & 133.504 & 22.7 & 17.2 & 0.156501 & 89.66 \\
\hline
\end{tabular}

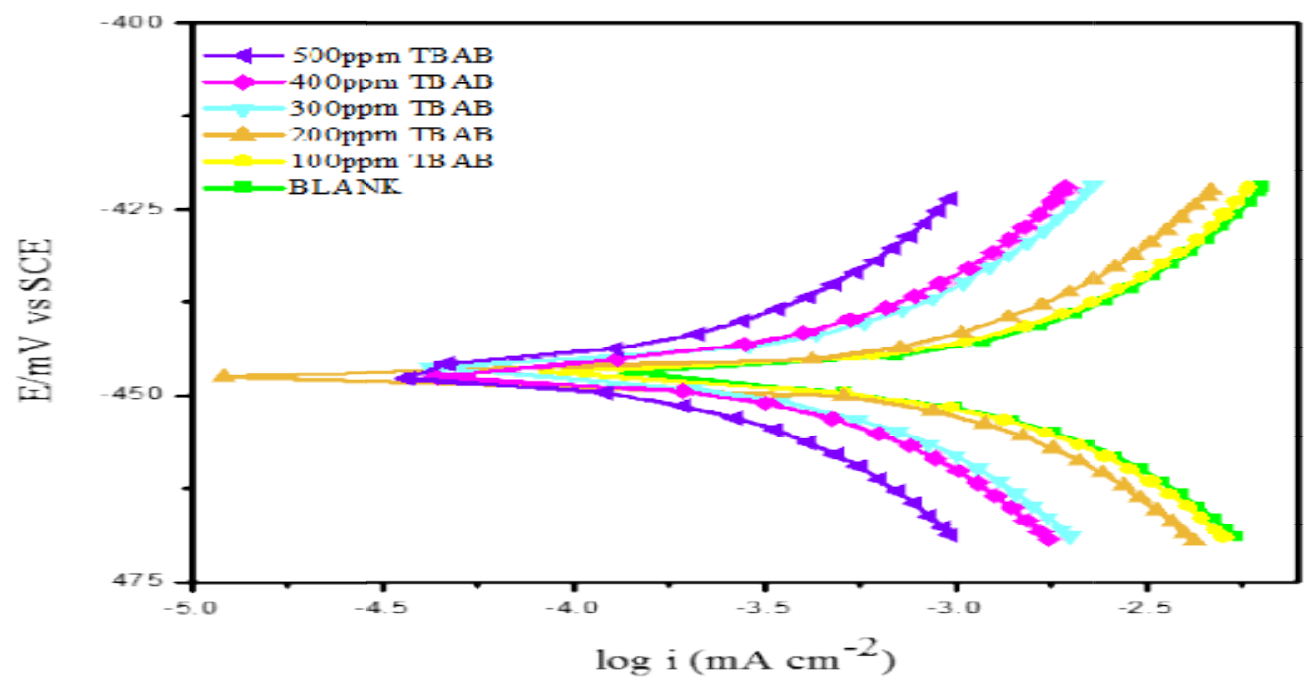

Fig.-6: Electrochemical Polarization Curves for Mild Steel Corrosion in $1 \mathrm{~N} \mathrm{HCl}$ in the Presence and Absence of TBAB

\section{Electrochemical Impedance Studies}

Mild steel corrosion in $1 \mathrm{~N} \mathrm{HCl}$ solution was studied at altered concentrations of TBAB using impedance spectra. The obtained results are reported in Fig.-7. From the figure clearly seen the size of the semicircle, concentrations of inhibitor revealed, in the size of the semicircle is bigger than that of uninhibited and the size of the semicircle rises with increasing concentrations of TBAB. Thus a rise in the values of charge transfer resistance is observed. All Nyquist spectra fitted with an equivalent circuit in Fig.-9. The equivalent circuit comprises Solution resistance $\left(R_{s}\right)$ and Double-layer capacitance $\left(C_{d l}\right)$ which is parallel to charge transfer resistance $\left(\mathrm{R}_{\mathrm{ct}}\right)$.

The double-layer capacitance of a circuit includes $\mathrm{R}_{\mathrm{ct}}$, which was calculated by the following equation: ${ }^{34}$ $\mathrm{C}_{\mathrm{dl}}=\frac{1}{2 \pi \mathrm{f}_{\max } \mathrm{R}_{\mathrm{ct}}}$

Where, $f_{\max }$ represents the maximum frequency of imaginary components of the impedance.

The inhibition efficiency of mild steel is calculated by the following equation,

$\operatorname{IE}(\%)=\frac{\mathrm{R}_{\mathrm{ct}}^{\prime}-\mathrm{R}_{\mathrm{ct}}}{\mathrm{R}_{\mathrm{ct}}^{\prime}} \times 100$

Where, $R_{c t}$ and $R_{c t}$ are the charge transfer values with and without TBAB respectively. 
RASĀYAN J. Chem.

Vol. 13 | No. 1 |499 - 513| January - March | 2020

Table-6 depicts Nyquist parameters, $R_{c t}$ value increases while $C_{d l}$ value decreases with an increasing inhibitor concentration. $\mathrm{C}_{\mathrm{dl}}$ value decreases, which is a result of TBAB that get adsorbed on the MS. The values of $\mathrm{C}_{\mathrm{dl}}$ are always smaller in inhibited metal than uninhibited. From Table- $6, \mathrm{C}_{\mathrm{dl}}$ value decreases from $20.40 \times 10^{-3} \mathrm{~cm}^{-2}$ to $2.34 \times 10^{-3} \mathrm{~cm}^{2}$. This indicates the rate of corrosion is low. $\mathrm{R}_{\mathrm{ct}}$ values increased from $3.30 \Omega . \mathrm{cm}^{2}$ to $10.19 \Omega . \mathrm{cm}^{2}$. This suggests that the inhibitor molecule is present at the MS/solution boundary. The inhibition efficiency increase is perceived to rise in TBAB. The maximum inhibition efficiency values were obtained at $67.57 \%$. Corresponding bode plots obtained from MS in $1 \mathrm{~N} \mathrm{HCl}$ with and without TBAB are presented in Figure 8. It was found that the phase plots contribute only one time constant at around $100 \mathrm{~Hz}$ and also peak broad wing is maximum with increasing TBAB concentration due to TBAB molecules adsorbed the surface of the specimen. Their adsorption is proportional to the inhibitor concentrations ${ }^{35-36}$ which ensures that the tested inhibitor exhibits good inhibiting performance for mild steel in $1 \mathrm{NHCl}$ solution. The results from impedance and polarization studies are in respectable covenant with weight loss method.

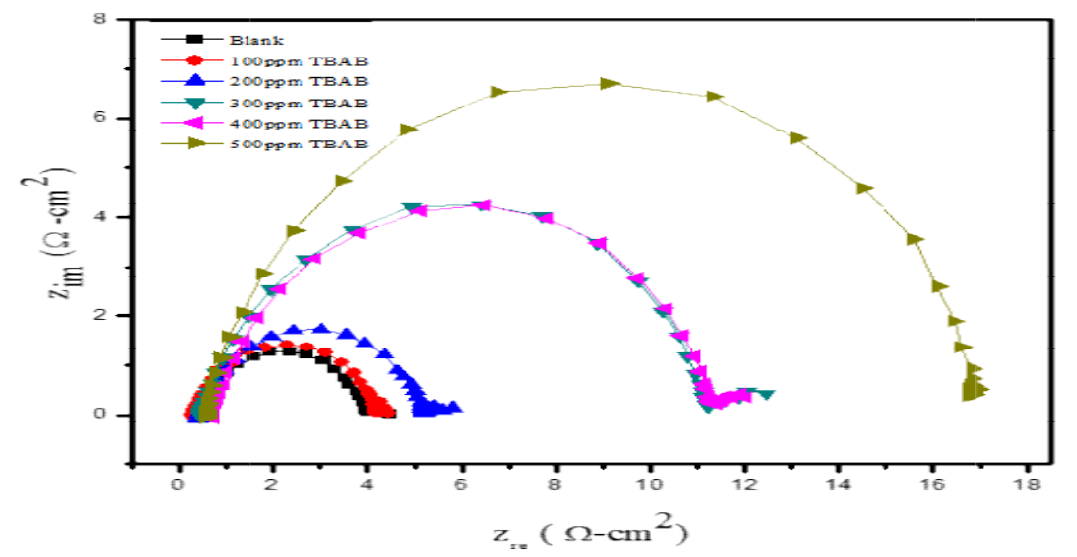

Fig.-7: Nyquist Plots for Mild Steel in $1 \mathrm{NHCl}$ containing Various Concentrations of TBAB
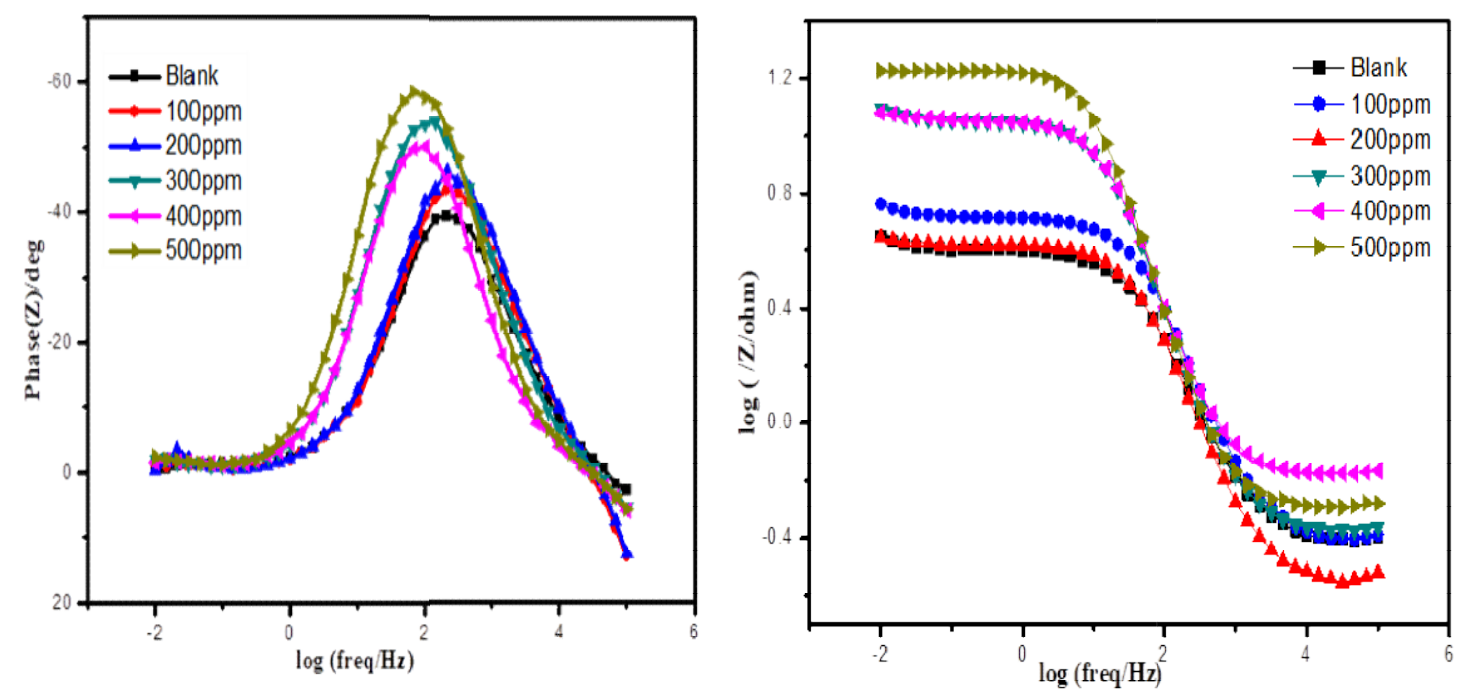

Fig.-8: Bode Impedance for Mild Steel in 1NHCl containing Different Concentrations of TBAB at $298 \mathrm{~K}$ Table-6: Impedance Parameters of Mild Steel in $1 \mathrm{~N} \mathrm{HCl}$ containing Various Concentrations of TBAB

\begin{tabular}{c|c|c|c}
\hline $\begin{array}{c}\text { Conc } \\
(\mathrm{ppm})\end{array}$ & $\begin{array}{c}\mathrm{R}_{\mathrm{ct}} \\
\left(\Omega . \mathrm{cm}^{2}\right)\end{array}$ & $\begin{array}{c}\mathrm{C}_{\mathrm{dl}} \\
\left(\mathrm{F} / \mathrm{cm}^{2}\right)\end{array}$ & $\begin{array}{c}\mathrm{IE} \\
(\%)\end{array}$ \\
\hline Blank & 3.30 & $20.40 \times 10^{-3}$ & - \\
\hline 100 & 3.66 & $18.86 \times 10^{-3}$ & 9.84 \\
\hline 200 & 4.50 & $11.72 \times 10^{-3}$ & 26.62 \\
\hline \multicolumn{4}{|c}{506}
\end{tabular}


RASĀYAN J. Chem.

Vol. 13 | No. 1 |499 - 513| January - March | 2020

\begin{tabular}{c|c|c|c}
\hline 300 & 9.05 & $2.74 \times 10^{-3}$ & 63.50 \\
\hline 400 & 10.13 & $2.42 \times 10^{-3}$ & 67.39 \\
\hline 500 & 10.19 & $2.34 \times 10^{-3}$ & 67.57 \\
\hline
\end{tabular}

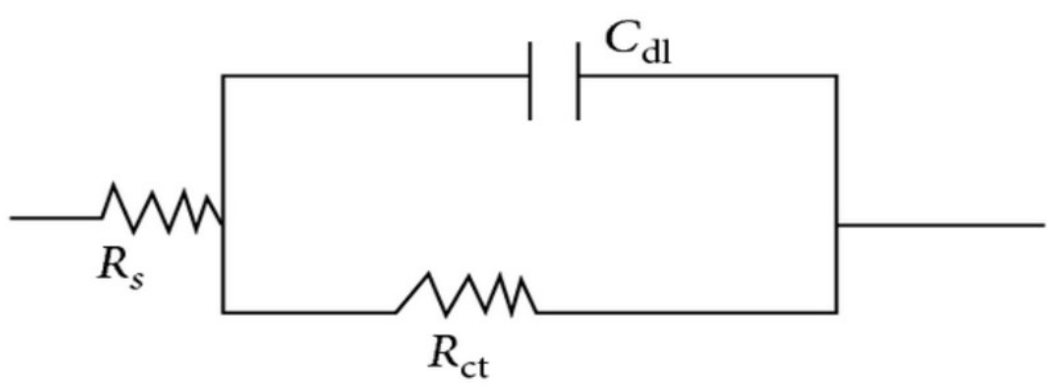

Fig.-9: Equivalent Circuit for Inhibited Mild Steel Sample

\section{FT-IR Analysis}

Fourier Transform Infra-Red analysis has been used to study the contact among TBAB and sample surface in the $1 \mathrm{~N} \mathrm{HCl}$ solution. Figure-10 show the spectra of mild steel immersed in $1 \mathrm{~N} \mathrm{HCl}$ with $500 \mathrm{ppm}$ of TBAB as well as the TBAB itself. As shown in Figure 10 (a) the bands at 3297, 1621 and 656 $\mathrm{cm}^{-1}$ are attributed to NH, C-H and C-C bonds of TBAB. The spectrum of inhibited metal in corrosive medium. Figure-10(b) shows the same peaks are shifted to 3413, 1642 and $698 \mathrm{~cm}^{-1}$ respectively. This indicates that $\mathrm{TBAB}$ adsorbed on the mild steel surface through the heteroatom of inhibitor. Hence it can stay assumed that the functional group of inhibitor takes synchronized by the surface of the mild steel ensuing in the development of a $\left[\mathrm{Fe}^{2+}-\mathrm{TBAB}\right]$ complex over the metal, which encourages the reserve of mild steel ${ }^{37}$

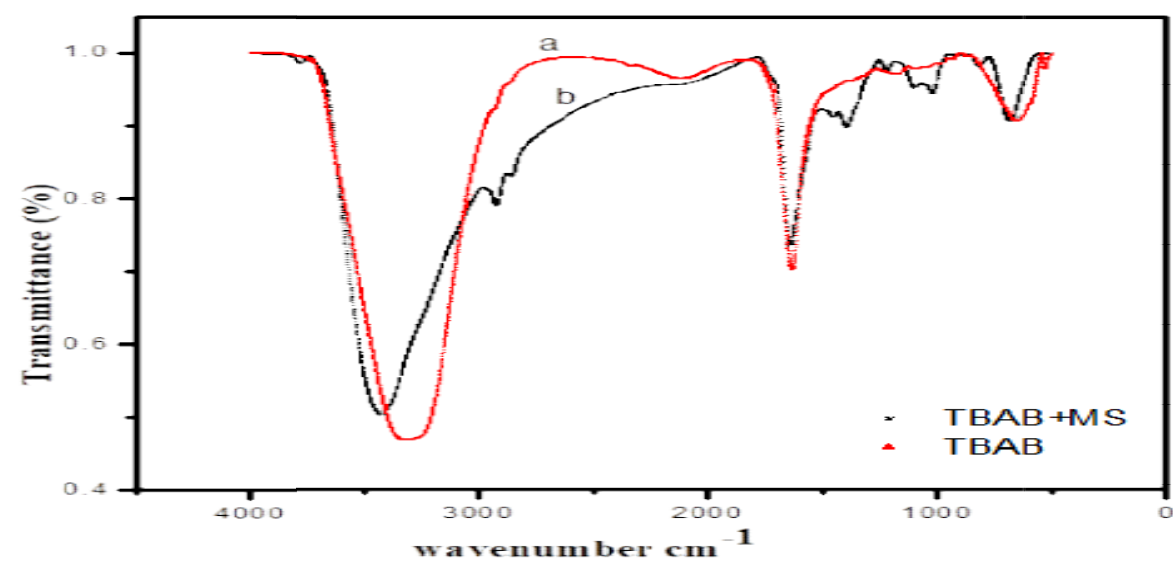

Fig.-10: FTIR Spectra for (a) TBAB and (b) Inhibited Mild Steel

\section{UV-Visible Spectroscopy}

Figure-11 shows the UV-visible absorption spectra for TBAB solution and the inhibited solution after immersion of mild steel in $1 \mathrm{~N} \mathrm{HCl}$ containing TBAB for about 1 hour. A hyperchromic shift was observed in the absorption band. This was due to the formation of the complex between the TBAB and $\mathrm{Fe}^{2+}$ in $1 \mathrm{~N} \mathrm{HCl}$ solution. ${ }^{38-39}$ Furthermore, there are no important deviations in the shape of the spectrum between the two solutions.

\section{XRD Analysis}

XRD was used to confirm the film made on the mild steel with or without TBAB, respectively. Figure-12 $\mathrm{b}$ shows a peak at $2 \Theta=51.41^{\circ}$ can be suggested for iron oxides. The peaks owing to Fe appear at $2 \Theta=$ $44.55^{\circ}, 64.78^{\circ}$, and $82.14^{\circ}$. It shows that the immersion of mild steel in $1 \mathrm{~N} \mathrm{HCl}$ without TBAB contains oxides of iron. Figure. 12 a demonstrate the inhibited mild steel with TBAB, an intense peak can be seen at $2 \Theta=44.42^{\circ}, 64.70^{\circ}, 82.04^{\circ}$ due to iron. ${ }^{40-41}$ However, the absence of peak around $51.41^{\circ}$ indicates the absence of iron oxides. These results also confirm the protective layer formed on the mild steel sample. 
RASĀYAN J. Chem.

Vol. 13 | No. 1 |499 - 513| January - March | 2020

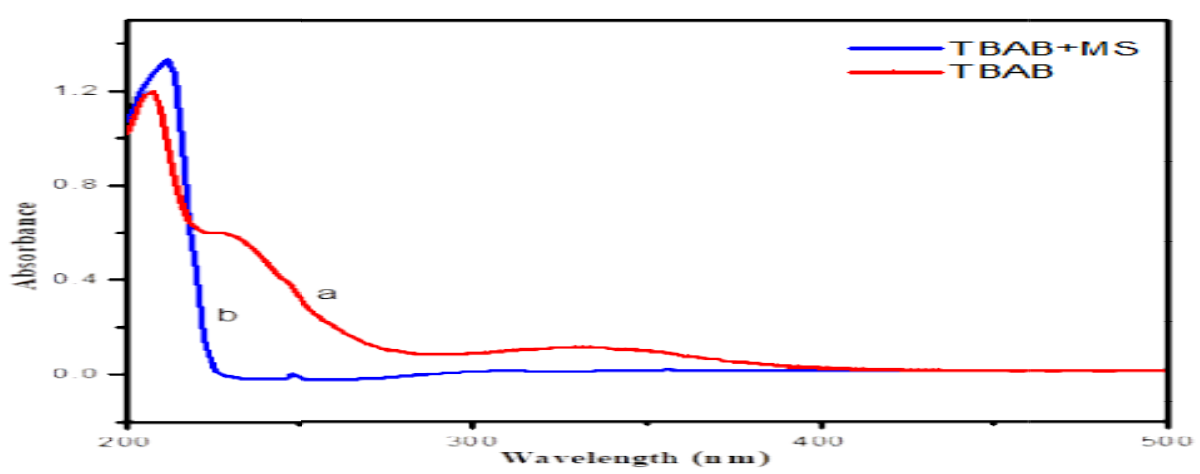

Fig.-11: UV-Visible Spectra for the Solution of (a) Pure TBAB and (b) Mild Steel in Inhibiting System

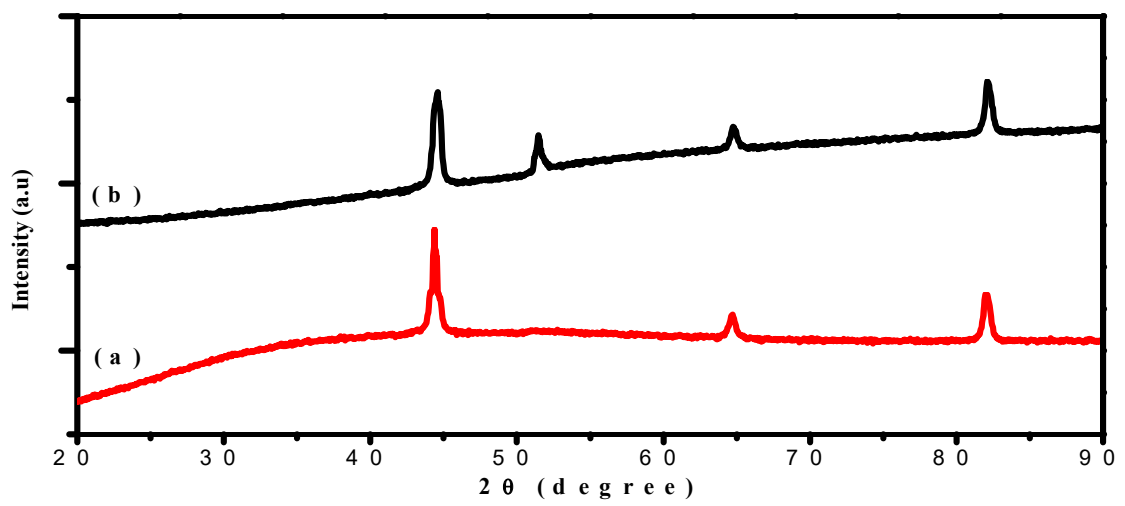

Fig.-12: XRD for Mild Steel After Immersion in $1 \mathrm{~N} \mathrm{HCl} \mathrm{(a)} \mathrm{in} \mathrm{the} \mathrm{Presence} \mathrm{and} \mathrm{(b)} \mathrm{the} \mathrm{Absence} \mathrm{of} \mathrm{TBAB}$

\section{SEM and EDAX Studies}

SEM and EDAX were used to check the formation of a defensive layer of TBAB taking place in the specimen. SEM image of mild steel in $1 \mathrm{~N} \mathrm{HCl}$ with and without TBAB for 1 hour period is shown in Fig.-13 and 14. Figure-13 shows that the metal was harshly rusted attributable to acid corrosion. The mild steel specimen surface was highly damaged and is full of roughness in the absence of an inhibitor. The corresponding EDAX spectrum shows the elements such as Fe, $\mathrm{C}$, and $\mathrm{O}$. The $\mathrm{Fe}$ and $\mathrm{C}$ peak is due to the constituent of the mild steel specimen, $\mathrm{O}$ peak shows the presence of corrosion products such as oxides of iron. The inhibited specimen surface was better than uninhibited specimen surface, because of the development of a protective film of TBAB that had adsorbed on a metal surface. The EDAX spectra (Fig.-14) shows only $\mathrm{Fe}$ and $\mathrm{C}$ peaks aimed at the specimen in $500 \mathrm{ppm}$ of TBAB in $1 \mathrm{~N} \mathrm{HCl}$. The absence of oxygen peak indicates that the corrosion products are restricted as a result of TBAB adsorbed taking place at a mild steel surface.

\section{AFM Analysis}

The 2D and 3D images of mild steel immersed in $1 \mathrm{~N} \mathrm{HCl}$ solution without and with $500 \mathrm{ppm}$ of TBAB for 1 hour at 298K are shown in Fig.-15. Figure-15a displays highly damaged surface of mild steel in $1 \mathrm{~N}$ $\mathrm{HCl}$, due to acid attack. However, with the addition of 250ppm of TBAB (Fig.-15 b), the mild steel surface is found with a smooth surface indicating the formation of a protective layer on the metal surface by the adsorption of TBAB. AFM parameters such as the root mean square roughness $\left(\mathrm{R}_{\mathrm{q}}\right)$, average roughness $\left(\mathrm{R}_{\mathrm{a}}\right)$, and maximum peak to valley height $\left(\mathrm{R}_{\mathrm{p}-\mathrm{v}}\right)$ for mild steel in the absence and presence of TBAB are given in Table-7. The values of $R_{q}, R_{a}$, and $R_{p-v}$ in the presence of inhibitor were decreased to $228.1,175.2$, and $146.49 \mathrm{~nm}$ from the respective values (276.6, 232.4, and $159.17 \mathrm{~nm}$ ) of uninhibited mild steel surface. This demonstrates TBAB as an effective corrosion inhibitor for mild steel in $1 \mathrm{~N} \mathrm{HCl}$ medium by the formation of a protective layer. 
RASĀYAN J. Chem.

Vol. 13 | No. 1 |499 - 513| January - March | 2020
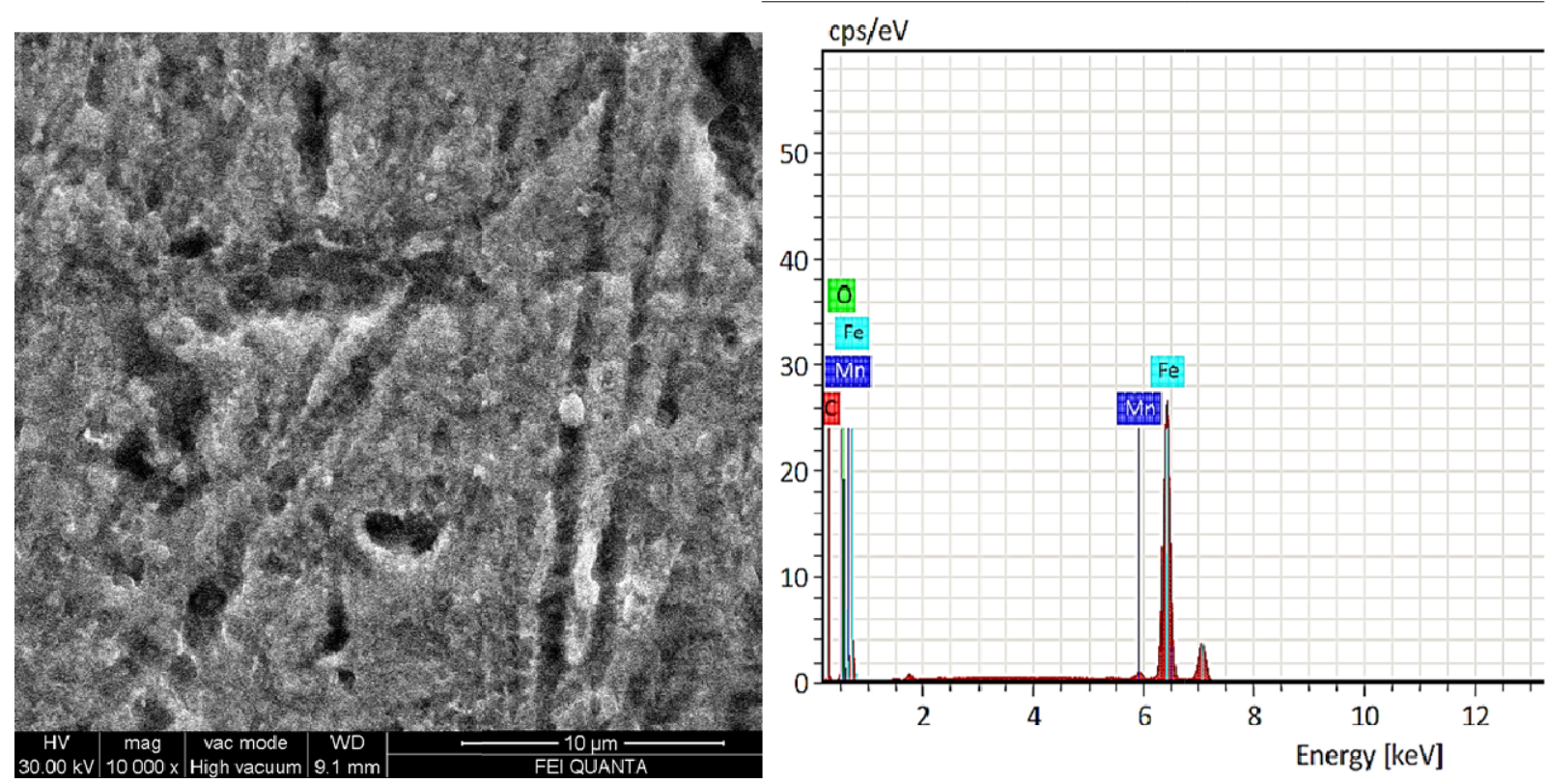

Fig.-13: SEM and EDAX of An Uninhibited Mild Steel Specimen
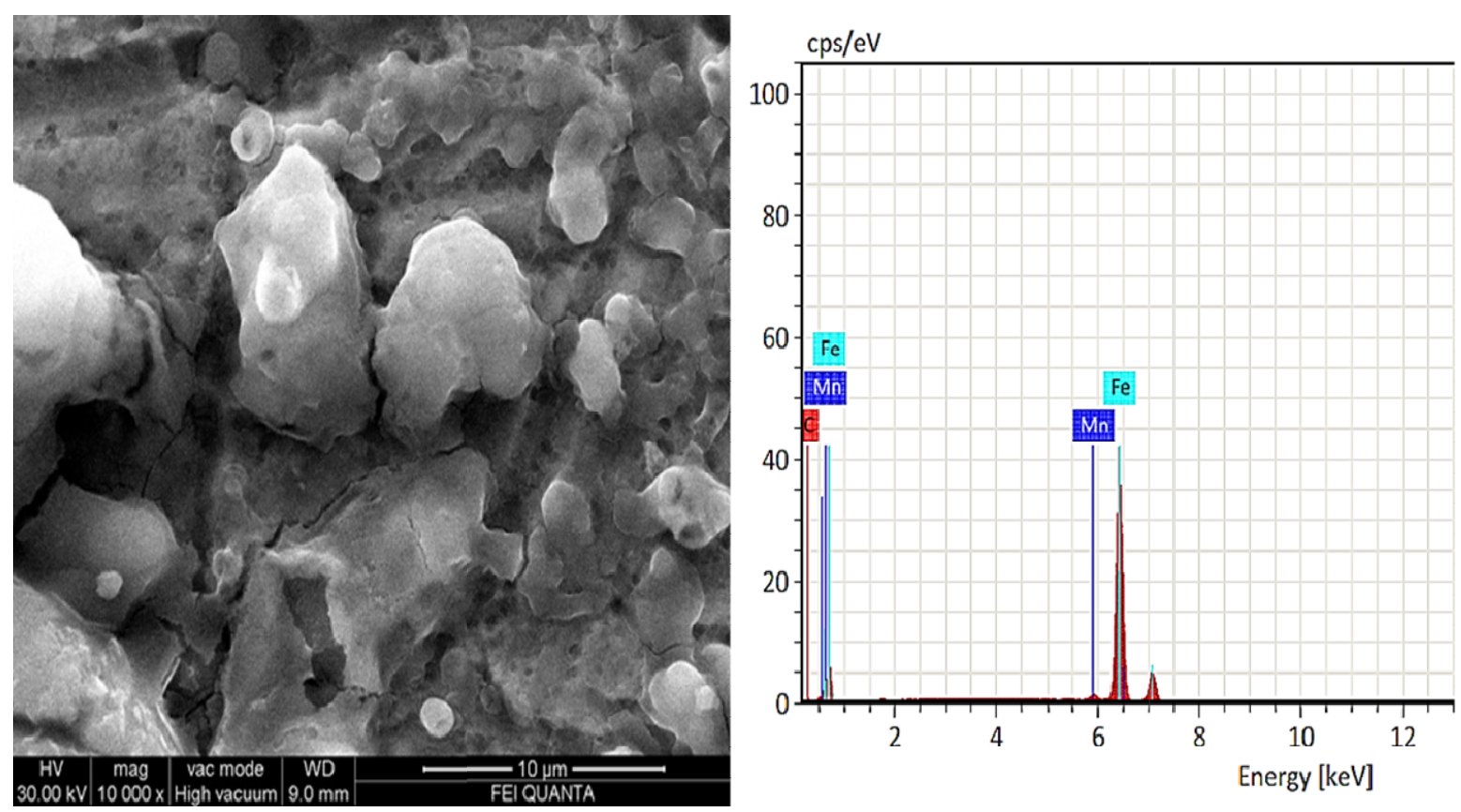

Fig.-14: SEM and EDAX for Inhibited Mild Steel Specimen

Table-7: AFM Roughness Parameters of Mild Steel

\begin{tabular}{c|c|c|c}
\hline Sample & $\mathrm{R}_{\mathrm{q}} / \mathrm{nm}$ & $\mathrm{R}_{\mathrm{a}} / \mathrm{nm}$ & $\mathrm{R}_{\mathrm{p}-\mathrm{v}} / \mathrm{nm}$ \\
\hline $1 \mathrm{~N} \mathrm{HCl}$ & 276.6 & 232.4 & 159.17 \\
\hline $1 \mathrm{~N} \mathrm{HCl}+\mathrm{TBAB}$ & 228.1 & 175.2 & 146.49 \\
\hline
\end{tabular}


RASĀYAN J. Chem.

Vol. 13 | No. 1 |499 - 513| January - March | 2020
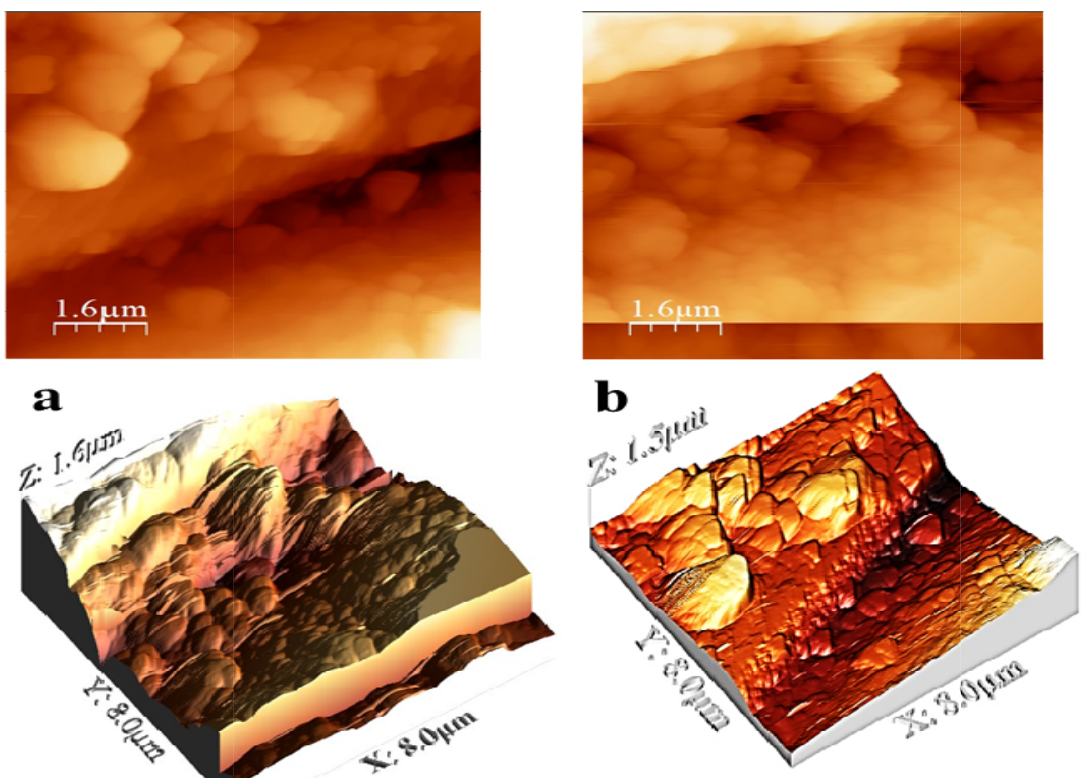

Fig.-15: 2D and 3D AFM Images of Mild Steel immersed in (a) $1 \mathrm{~N} \mathrm{HCl}$ and (b) presence of TBAB.

\section{Quantum Mechanical Studies}

Quantum mechanical studies were carried out to elucidate the microscopic molecular structure of TBAB. The optimized structure of TBAB is depicted in Fig.-16. The HOMO (Highest Occupied Molecular Orbital) and LUMO (Lowest Occupied Molecular Orbital) are shown in Fig.-17. The calculated $\mathrm{E}_{\text {номо, }}$ $\mathrm{E}_{\mathrm{LUMO}}, \Delta \mathrm{E}, \mu, \mathrm{I}, \mathrm{A}, \chi, \eta$, and $\Delta \mathrm{N}$ are presented in Table- 8 .

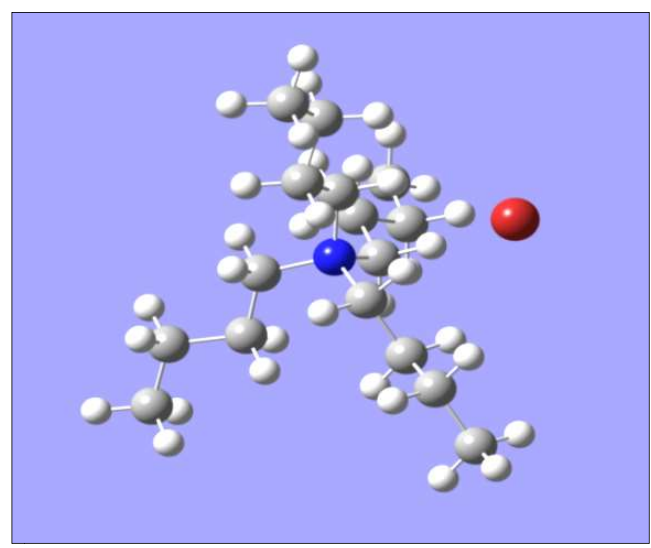

Fig.-16: Optimized Structure of TBAB

$\mathbf{a}$

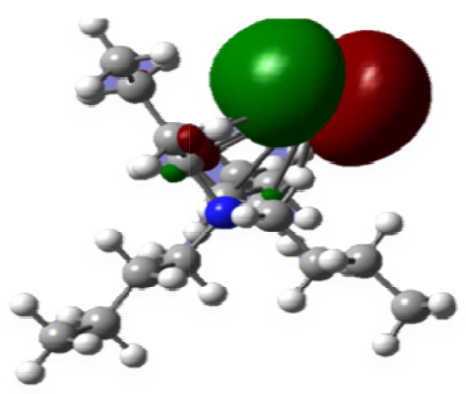

$\mathbf{b}$

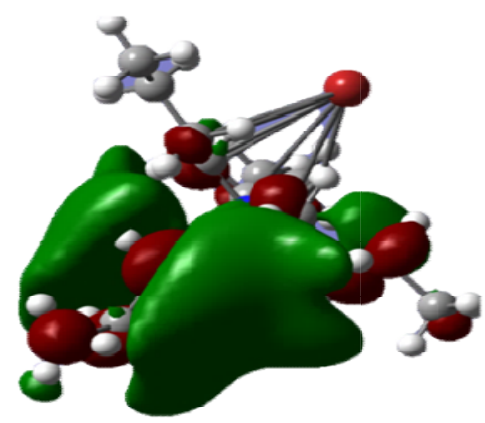

Fig.-17: (a) HOMO, (b) LUMO of TBAB 
RASĀYAN J. Chem.

Vol. 13 | No. 1 |499 - 513| January - March | 2020

The molecular orbital energies $\mathrm{E}_{\mathrm{HOMO}}$ and $\mathrm{E}_{\mathrm{LUMO}}$, describe the chemical reactivity of the corrosion inhibitor molecules. It is seen from Fig. 17 that the LUMO orbitals of TBAB spread over the entire molecule. On the other hand, the HOMO of TBAB is on the bromide ion. Hence, the interaction of TBAB with the positively charged mild steel surface is through $\mathrm{Br}^{-}$ion. The $\mathrm{E}_{\text {Hомо }}$ and $\mathrm{E}_{\mathrm{LUMO}}$ calculated from DFT analysis were determined to be -4.38 and $1.20 \mathrm{eV}$, respectively. Thus the charge transferred from $\mathrm{HOMO}$ to empty orbitals of $\mathrm{Fe}$ atom. Furthermore the lower energy gap, $\Delta \mathrm{E}=5.58 \mathrm{eV}$ can be associated with the electron transfer and chemical reactivity of the TBAB molecule. Energy gap value in the range of 6.40 to $3.38 \mathrm{eV}$ showed higher inhibition efficiency ${ }^{42}$ and thus develops an electrostatic interaction between TBAB and mild steel. The value of $\Delta \mathrm{N}=0.9690(<3.6)^{43}$ indicates the tendency of TBAB donates electrons to the metal surface. As per the reported literature, lower electronegativity $(\chi)$, lower global hardness $(\eta)$ and higher dipole moment $(\mu)$ values of inhibitor molecule favor their inhibition performance due to stronger metal-inhibitor binding ${ }^{44}$. The higher the dipole moment $(\mu=11.7128 \mathrm{D})$ than that of a water molecule $(\mu=1.8546 \mathrm{D}){ }^{45}$ has higher abilities to react with metal surface physically or chemically. Hence, this indicates that the TBAB gets strongly adsorbed on the mild steel surface by replacing the water molecules. Minimum $\chi$ value shows higher electron density and higher inhibition efficiency. TBAB has a minimum $\chi$ value of $1.59 \mathrm{eV}$ compared to the $\chi$ value of $\mathrm{Fe} 7 \mathrm{eV}$. ${ }^{46}$ Thereby, the electron transfer continues till the chemical potential becomes equal Hence minimum the $\chi$ value, higher will be the inhibition efficiency.

\begin{tabular}{c|c}
\multicolumn{2}{c}{ Table-8: Quantum Chemical Data of TABA } \\
\hline Parameters & Value \\
\hline $\mathrm{E}_{\mathrm{HOMO}}, \mathrm{eV}$ & -4.38156 \\
\hline $\mathrm{E}_{\mathrm{LUMO}}, \mathrm{eV}$ & 1.20123 \\
\hline$\Delta \mathrm{E}, \mathrm{eV}$ & 5.58279 \\
\hline$\mu, \mathrm{D}$ & 11.7128 \\
\hline $\mathrm{I}, \mathrm{eV}$ & 4.38156 \\
\hline $\mathrm{A}, \mathrm{eV}$ & -1.20123 \\
\hline$\chi, \mathrm{eV}$ & 1.59016 \\
\hline$\eta, \mathrm{eV}$ & 2.79139 \\
\hline$\Delta \mathrm{N}$ & 0.96902 \\
\hline
\end{tabular}

\section{CONCLUSION}

Tetra-n-butyl ammonium bromide has been studied as a corrosion inhibitor for mild steel in $1 \mathrm{~N} \mathrm{HCl}$ medium by experimental and theoretical methods. The experimental outcomes display that TBAB performance by way of a competent inhibitor for mild steel corrosion and attain an extreme inhibition efficiency of $93 \%$ at $500 \mathrm{ppm}$ concentration. Adsorption of TBAB molecules of the mild steel follows the Langmuir isotherm. The values of $\Delta \mathrm{G}_{\text {ads }}$ less than $-20 \mathrm{~kJ} \mathrm{~mol}^{-1}$ reveal that the adsorption of TBAB on the MS is impulsive and predominantly occurs by physisorption. EIS results point out that corrosion inhibition of TBAB takes place due to the creation of a defensive coating. Tafel results show that the investigated TBAB is a mixed type inhibitor. UV-Visible spectra suggest metal- inhibitor interactions, while AFM and SEM images were confirmed that the TBAB protects the mild steel surface from metal corrosion. Quantum chemical studies that recommend that adsorption of TBAB happen through $\mathrm{Br}^{-}$ion. Theoretical calculations are made in respectable covenant with the experimental outcomes.

\section{ACKNOWLEDGMENT}

We acknowledge the Nanotechnology Research Centre (NRC), SRMIST for providing AFM and SEMEDAX facilities.

\section{REFERENCES}

1. J. Haque, V. Srivastava, C. Verma, H. Lgaz, R. Salghi and M.A. Quraishi, New Journal of Chemistry, 41, 22 (2017), DOI: 10.1039/C7NJ02254A

2. P. Dohare, M.A. Quraishi and I.B. Obot, Journal of Chemical Sciences, 130, 1 (2018), DOI: 10.1007/s12039-017-1408-x

3. P. Han, C. Chen, W. Li, H. Yu, Y. Xu, L. Ma and Y. Zheng, Journal of Colloid and Interface 511 
RASĀYAN J. Chem.

Vol. 13 | No. 1 |499 - 513| January - March | 2020

Science, 516, 15 (2018), DOI: 10.1016/j.jcis.2018.01.088

4. H. Jafari, I. Danaee, H. Eskandari and M. RashvandAvei, Industrial \& Engineering Chemistry Research, 52, 20 (2013), DOI:10.1021/ie400066x

5. H. El Attari, S. Mengouch, M. Siniti, E. Zahidi, L. Khamliche and A. Kheribech, Journal of Materials and Environmental Science, 9, 2 ( 2018), DOI:10.26872/jmes.2018.9.2.76

6. S. Cao, D. Liu, P. Zhang, L. Yang, P. Yang, H. Lu and J. Gui, Scientific Reports, 7, 1 (2017), DOI: 10.1038/s41598-017-07925-y

7. Y. Meng, W. Ning, B. Xu, W. Yang, K. Zhang, Y. Chen, L. Li, X. Liu, J. Zheng and Y. Zhang, RSC Advances, 7, 68 (2017), DOI: 10.1039/C7RA08170G

8. M.A. Deyab, A.S. Fouda, M.M. Osman and S.Abdel-Fattah, RSC Advances, 7, 71 (2017), DOI: 10.1039/C7RA08761F

9. M.T. Alhaffar, S.A. Umoren, I.B. Obot and S.A. Ali, RSC Advances, 8, 4 (2018), DOI: 10.1039/C7RA11549K

10. H.U. Nwankwo, L.O. Olasunkanmi and E.E. Ebenso, Scientific Reports, 7, 1 (2017), DOI: 10.1038/s41598-017-02446-0

11. A. Pandey, B. Singh, C. Verma and E.E. Ebenso, RSC Advances, 7, 74 (2017), DOI: 10.1039/C7RA08887F

12. L.C. Murulana, M.M. Kabanda and E.E. Ebenso, RSC Advances, 5, 36 (2015), DOI: 10.1039/C4RA11414K

13. Q.B. Zhang and Y.X. Hua, Electrochimica Acta, 54, 6 (2009), DOI: 10.1016/j.electacta.2008.10.025

14. R. Fuchs Godec, M.G. Pavlovic and M.V. Tomic, Industrial \& Engineering Chemistry Research, 51, 1 (2011), DOI: $10.1021 /$ ie2015697

15. A. Yousefi, S.Javadian and J. Neshati, Industrial \& Engineering Chemistry Research, 53, 13 (2014), DOI: $10.1021 /$ ie $402547 \mathrm{~m}$

16. F.E. Heakal, M.A. Deyab, M.M. Osman, M.I. Nessim and A.E. Elkholy, RSC Advances, 7, 75 (2017), DOI:10.1039/C7RA07176K

17. C.Verma, M.A. Quraishi, K. Kluza, M. Makowska-Janusik, L.O. Olasunkanmi and E.E. Ebenso, Scientific Reports, 44432, 7 (2017), DOI: 10.1038/srep44432

18. G. Raja, K. Saravanan and S.Sivakumar, Rasayan Journal of Chemistry, 8, 1 (2015)

19. N. Subasree, J. Arockia Selvi, P. Kamaraj and M. Arthanareeswari, International Journal of ChemTech Research, 11, 02 (2018), DOI: 10.20902/IJCTR.2018.110238

20. S. Bouakkaz, R. Zerdoumi, K. Oulmi, D. Mellahi and G.M. Andreadis, Portugaliae Electrochimica Acta, 35, 4 (2017), DOI: 10.4152/pea.201704211

21. M. J. Frisch, G. W. Trucks, H. B. Schlegel, G. E. Scuseria, M. A. Robb, J. R. Cheeseman, G. Scalmani, V. Barone, G A. Petersson, H Li X. Nakatsuji, M . Caricato, A V. Marenich, J. Bloino, B G. Janesko, R. Gomperts, B. Mennucci, H. P. Hratchian, J. V. Ortiz, A F. Izmaylov, J L. Sonnenberg, D. Williams-Young, F. Ding, F. Lipparini, F. Egidi, J. Goings, B. Peng, A. Petrone, T. Henderson, D. Ranasinghe, V. G. Zakrzewski, J. Gao, N. Rega, G. Zheng, W. Liang, M. Hada, M. Ehara, K. Toyota, R. Fukuda, J. Hasegawa, M. Ishida, T. Nakajima, Y. Honda, O. Kitao, H. Nakai, T. Vreven, K. Throssell, J A Jr. Montgomery, J E. Peralta, F. Ogliaro, M. J. Bearpark, J. J .Heyd, E. N. Brothers, K N. Kudin, V N. Staroverov, T A. Keith, R. Kobayashi, J. Normand, K. Raghavachari, A .P .Rendell, J. C. Burant, S. S. Iyengar, J. Omasi J, M. Cossi, J. M. Millam, M. Klene, C. Adamo, R. Cammi, J. W. Ochterski, R. L. Martin, K. Morokuma, O. Farkas, J. BForesman, D. J. Fox, Gaussian, Inc., and Wallingford CT, (2016)

22. A. D. Becke, Journal of Chemical Physics, 5648, 98 (1993), DOI: 10.1063/1.464913

23. C. T. Lee, W. T. Yang and R. G. Parr, Physical Review. B, 37, 2 (1988), DOI: 10.1103/PhysRevB.37.785

24. A. Soni, P .Sharma, R. Dashora and A.K. Goswami, Portugaliae Electrochimica Acta, 35, 2 (2017), DOI: $10.4152 /$ pea.201702117

25. H.S. Gadow, M.M. Motawea and H.M. Elabbasy, Rsc Advances, 7, 47 (2017), DOI: 10.1039/C7RA04271J 
RASĀYAN J. Chem.

Vol. 13 | No. 1 |499 - 513| January - March | 2020

26. Najoua Labjar, Fouad Bentiss, Mounim Lebrini, Charafeddine Jama and Souad El hajjaji, International Journal of Corrosion, 548528, (2011), DOI:10.1155/2011/548528

27. R. Karthikaiselvi and S. Subhashini, Journal of the Association of Arab Universities for Basic and Applied Sciences, 16, 1 (2014), DOI:10.1016/j.jaubas.2013.06.002

28. K. Kalaiselvi, V. Nijarubini, and J. Mallika, Rasayan Journal of Chemistry, 6 , 1 (2013)

29. A. Yurt, B. Duran and H. Dal, Arabian Journal of Chemistry, 7, 5 (2014), DOI: 10.1016/j.arabjc.2010.12.010

30. M.E. Mashuga, L.O. Olasunkanmi and E.E. Ebenso, Journal of Molecular Structure, 1136, (2017), DOI: $10.1016 /$ j.molstruc.2017.02.002

31. H. Elmsellem, M. H. Youssouf, A. Aouniti, T. Ben Hadda, A. Chetouani and B. Hammouti, Russian Journal of Applied Chemistry, 87, 6 ( 2014), DOI: 10.1134/S1070427214060147

32. K.F. Khaled and M.M. Al-Qahtani, Materials Chemistry and Physics, 113, 1 (2009), DOI: 10.1016/j.matchemphys.2008.07.060

33. F. Wedian, M.A. Al-Qudah and A.N. Abu-Baker, Portugaliae Electrochimica Acta, 34, 1 (2016), DOI: $10.4152 /$ pea.201601039

34. M. Abdallah, I. Zaafarany, J.H. Al-Fahemi, Y. Abdallah and A.S. Fouda, International Journal of Electrochemical Science, 7, (2012)

35. P. Muthukrishnan, P. Prakash, B. Jeyaprabha and K. Shankar, Arabian Journal of Chemistry, (2015), DOI: 10.1016/j.arabjc.2015.09.005

36. W. Zhang, Li HJ, Y. Wang, Y. Liu and Wu YC, Materials and Corrosion, 69, 11 (2018), DOI: $10.1002 / \mathrm{maco} .201810252$

37. O. Olivares-Xometl, E. Álvarez-Álvarez, N.V. Likhanova, I.V. Lijanova, R.E. Hernández-Ramírez, P. Arellanes-Lozada and J.L. Varela-Caselis, Journal of Adhesion Science and Technology, 32, 10 (2018), DOI:10.1080/01694243.2017.1397422

38. A. Aloysius, R. Ramanathan, A. Christy, S. Baskaran and N. Antony, Egyptian Journal of Petroleum 27, 3 (2018), DOI:10.1016/j.ejpe.2017.06.003

39. R. Thilagavathi, A. Prithiba and R. Rajalakshmi, Rasayan Journal of Chemistry, 12, 2 (2019), DOI: 10.31788/RJC.2019.1225133

40. P. Muthukrishnan, B. Jeyaprabha and P. Prakash, Arabian Journal of Chemistry, 10, 2 (2017), DOI: 10.1016/j.arabjc.2013.08.011

41. K. Vinothkumar and M.G. Sethuraman, Materials Today Communications, 14, (2018), DOI: 10.1016/j.mtcomm.2017.12.007

42. Luna M. Corrales, Tu. Le Manh, R. Cabrera Sierra, J.V. Medina Flores, L. Lartundo Rojas and E.M. Arce Estrada, Journal of Molecular Liquids, 289, (2019), DOI: 10.1016/j.molliq.2019.111106

43. M. A. Bedair, Journal of Molecular Liquids, 219, (2016), DOI: 10.1016/j.molliq.2016.03.012

44. Tasic, Z. Zaklina, B. Marija, Petrovic Mihajlovic, B. Milan, Radovanovic, Ana T. Simonovic and M. Milan, Journal of Molecular Structure, 1159, (2018), DOI: 10.1016/j.molstruc.2018.01.031

45. Salman, A. Taghried, F. Khalida, Al-Azawi, Iman Mahdi Mohammed, Shaimaa B. Al-Baghdadi, Ahmed A. Al-Amiery, Tayser Sumer Gaaz and Abdul Amir H. Kadhum, Results in Physics, 9, (2018), DOI: $10.1016 /$ j.rinp.2018.02.055

46. Ahamad Ishtiaque, Rajendra Prasad and M. A. Quraishi, Corrosion Science, 52, 4 (2010), DOI: 10.1016/j.corsci.2010.01.015

[RJC-5485/2019] 